Research Article

\title{
Polymodal Activation and Desensitization of TRPV1 Receptor in Human Odontoblasts-Like Cells with Eugenol
}

\author{
Karen L. Latorre $(i D)$ and Paula A. Baldion (iD \\ Grupo de Investigaciones Básicas y Aplicadas en Odontología (IBAPO), Universidad Nacional de Colombia, Bogotá, Colombia \\ Correspondence should be addressed to Paula A. Baldion; pabaldione@unal.edu.co
}

Received 18 September 2020; Revised 10 November 2020; Accepted 21 December 2020; Published 29 December 2020

Academic Editor: Cheng-Chia Yu

Copyright (c) 2020 Karen L. Latorre and Paula A. Baldion. This is an open access article distributed under the Creative Commons Attribution License, which permits unrestricted use, distribution, and reproduction in any medium, provided the original work is properly cited.

\begin{abstract}
Dentinal hypersensitivity is a frequent reason for dental consultation, and its pathophysiology has not been fully clarified. Previous findings have made it possible to establish a relationship between the cellular sensory capacity and the activation of the polymodal transient receptor potential vanilloid 1 (TRPV1), which is responsible for the nociceptive response and whose desensitization could cause analgesia. Thus, the objective of this study was to determine the expression, localization, and functional activity of TRPV1 in human odontoblasts-like-cells (hOLCs) and the effect of eugenol (EUG) on its activation and desensitization. Human dental pulp stem cells (hDPSCs) were obtained from third molars and were characterized using flow cytometry, and their differentiation potential toward the osteoblastic, chondrogenic, and adipogenic lineages was investigated. Subsequently, the hDPSCs underwent odontogenic differentiation for 7, 14, and 21 days, and their phenotype (odontogenic markers dentin matrix protein-1 (DMP-1) and dentin sialoprotein (DSP)) was evaluated using immunofluorescence. The TRPV1 gene expression in hOLCs was estimated using RT-qPCR, and its localization was analyzed using immunofluorescence. Half-maximal effective concentration (EC50) from both eugenol (EUG) and capsaicin (CAP) was determined; in addition, receptor activation was evaluated against chemical, thermal, and $\mathrm{pH}$ stimuli. For the statistical analysis, a one-way ANOVA with a Tukey post hoc test $(p<0.05)$ was used. After establishing the in vitro model of hOLCs and the membrane location of TRPV1, its chemical activation with EUG and CAP was demonstrated, as well as its thermal activation at $\geq 43^{\circ} \mathrm{C}$ and with an acidic $(<6)$ or basic $\mathrm{pH}$ (between 9 and 12). Receptor desensitization was achieved after $20 \mathrm{~min}$ of exposure to two concentrations of EUG $(603.5$ and $1000 \mu \mathrm{M})$. These findings represent a stepping-stone for the construction of a pulp pain study model oriented toward a therapeutic alternative for the treatment of dentinal hypersensitivity.
\end{abstract}

\section{Introduction}

Dentinal hypersensitivity continues to be a frequent reason for dental consultations. It occurs as a short, transitory, and acute pain that affects $8-57 \%$ of the adult population. Despite its high prevalence, the exact cause of this exacerbated nociceptive response to external stimuli, whether chemical, thermal, or mechanical, is not yet known [1]. Three main theories have been postulated to explain this physiopathogenesis: the first, named "Nerve theory," explains sensitivity as a result of direct stimulation of the afferent nerve fibers; the second one, named "Hydrodynamic theory," attributes sensitivity to the stimulation of the nervous endings due to the movement of the dentinal fluid, which is present in the dentinal tubes; and the third, named "Odontoblast theory," in which the odontoblast (OD) itself is proposed as a receptor and signal transducer cell $[1,2]$. Each of these theories has its flaws. On the one hand, although the most widely accepted is the hydrodynamic theory, the sensitivity does not account for the variability in the dentinal response against different natured stimuli. On the other hand, regarding the nerve theory, the sensitivity is difficult to explain because the penetration of the nerve endings seems to be limited to the deep dentin, which would render the surfaces that could be exposed to stimuli as innervated, which are the surface of the dentin and, eventually, the middle section of it. Regarding the viability of the odontoblast theory, recent findings allow us to glimpse the possibility that odontoblasts may, in fact, 
be sensory cells capable of triggering intracellular molecular responses to these external stimuli. This theory appears to be supported by recent studies that have shown the presence of transient receptor potential cation channel (TRP) membrane receptors in ODs, which in turn, have been localized in rat, mice, and human ODs using in vitro experiments, and they seem to be related to this nociceptive response [2-8].

The transient receptor potential vanilloid 1 (TRPV1) is characterized by its polymodal activation against chemical, thermal, mechanical, and $\mathrm{pH}$-variation stimuli in neuronal cultures from human trigeminal ganglion (GT) [9], in rat and mouse dental primary afferent neurons $[5,10]$. Regarding chemical stimulation, the most studied vanilloid agonist for chemical stimulation is capsaicin (CAP), which has a vanilloid functional group [3-8]. Additionally, it has been used to describe a desensitization process of the receptor, which would cause an analgesic effect [11]. Considering the structure-activity relationship, it is hypothesized that this receptor would also be activated with other molecules with a vanilloid functional group, such as eugenol (EUG). EUG is a phenolic vanilloid compound widely used in dentistry, and it has been described as an activator of the TRPV1 receptor in HEK-293 transfected cells; however, its effect has not yet been studied in cells with an odontoblast phenotype [12].

Considering all of the above information, issues arise: first, the proposed theories might not precisely clarify the inherent molecular process underlying pathology, as there seems to be a gap of knowledge regarding this topic $[1,2]$. Second, various therapeutic strategies have been developed, such as the application of topical fluoride, "desensitizing" toothpastes, gels, varnishes, or composite resin restorations. However, due to their high therapeutic failure frequency, these alternatives have not been able to solve the problem [1]. Finally, there is no availability of a functional analysis of the polymodal activation of the TRPV1 receptor in human odontoblast like-cells (hOLCs) and, specifically, using EUG - in the case of chemical stimulation- [12] all of which motivated the present investigation.

Consequently, the proposed aim was to determine the expression, location, and functional activity of the pain receptor TRPV1 in an in vitro model of hOLCs by subjecting them to chemical stimuli with CAP and EUG, thermal stimuli, and exposure to several $\mathrm{pHs}$. We aimed to propose a model for the study of pulp pain, providing valuable information that can be used to develop a therapeutic alternative for the treatment of dentinal hypersensitivity.

\section{Materials and Methods}

2.1. Obtaining Human Dental Pulp Stem Cells (hDPSCs). Following the protocol proposed by Baldion et al. 2018 [13], healthy human third molars, free of caries and restorations, with the indicated extraction of patients between 14 and 18 years of age, with prior informed consent and endorsement of the Institutional Ethics Committee (B.CIEFO-122-18) were obtained. The teeth were decontaminated, and the pulp was extracted and immersed in Dulbecco's Modified Eagle Culture Medium (DMEM) low in glucose (Hyclone, Thermo
Scientific, Bremen, Germany), supplemented with fetal bovine serum (FBS) (Gibco; Thermo Fisher Scientific) at $10 \%$ and antibiotics, in a dissociation medium with collagenase $(3 \mathrm{mg} / \mathrm{ml})$ and dispase $(4 \mathrm{mg} / \mathrm{ml})$ (Sigma-Aldrich; $\mathrm{St}$ Louis, MO, USA) for $16 \mathrm{~h}$ in an incubator with a humidified atmosphere with $5 \%$ carbon dioxide $\left(\mathrm{CO}_{2}\right)$ at $37^{\circ} \mathrm{C}$. The cell suspension was centrifuged, and the pellet was resuspended to be seeded in $25 \mathrm{~cm}^{2}$ flasks, making subcultures until reaching $70 \%$ confluence. To evaluate the behavior of cell proliferation, the population doubling time (PDT) was calculated by counting with a hemocytometer using trypan blue (Gibco, Thermo Fisher Scientific) applying the following formula: $\left(t_{2}-t_{1}\right) / 3.32 \times\left(\log n_{2}-\log n_{1}\right)$ where $t$ corresponds to the days in culture and $n$ the number of cells, the result was verified using the Doubling Time software [14].

The hDPSCs were characterized using flow cytometry according to the criteria of the International Society for Cell Therapy [15], with the use of the FACSCalibur cytometer (BD Biosciences; San Jose, CA, USA) and a phenotyping cocktail (Miltenyi Biotec; Bergisch Gladbach, Germany) that included antibodies to detect the markers CD73, CD90, CD105, CD34, CD14, CD20, and CD45. In order to corroborate the undifferentiated mesenchymal phenotype and its potential for differentiation toward different lineages. Differentiation toward the osteoblastic, chondroblastic, and adipoblastic phenotype was induced for 21 days. The StemPro ${ }^{\circledR}$ Osteogenesis Differentiation Kit (Gibco, Thermo Fisher Scientific) differentiation medium was used to obtain the osteoblast culture, which was stained with alizarin red (Sigma-Aldrich) in order to evaluate calcification nodules and mineralized matrix formation. The StemPro ${ }^{\circledR}$ Chondrogenesis differentiation kit (Gibco, Thermo Fisher Scientific) was used to obtain chondrocytes, and the Alcian Blue stain (Sigma-Aldrich) was performed in order to identify their ability to proteoglycans synthesize. Finally, to obtain adipocytes, the differentiation medium StemPro ${ }^{\circledR}$ Adipogenesis differentiation kit (Gibco, Thermo Fisher Scientific) was used, and an Oil RedO stain (Sigma-Aldrich) was carried out in order to identify neutral lipids. Images were obtained with the Leica DM2500 Microscope (Leica Microsystems; Wetzlar, Germany) [16].

\subsection{Differentiation Process of hDPSCs to hOLCs. A DMEM} medium was used, supplemented with FBS, $100 \mathrm{U} / \mathrm{ml}$ penicillin, and $100 \mathrm{ug} / \mathrm{ml}$ streptomycin; $0.1 \mu \mathrm{M}$ dexamethasone (Sigma-Aldrich), $5 \mathrm{mM} \beta$-glycerophosphate (Santa Cruz, CA, USA), $50 \mu \mathrm{g} / \mathrm{mL}$ ascorbic acid (Sigma-Aldrich), and $10 \mathrm{ng} / \mathrm{mL}$ TGF- $\beta 1$ (Abcam, Cambridge, MA, USA). The hDPSCs were exposed to the differentiation medium for 7 , 14 , and 21 days in an incubator at $37^{\circ} \mathrm{C}$ in a humidified atmosphere containing $5 \% \mathrm{CO}_{2}$ [13], and the behavior of the TRPV1 receptor expression within the differentiation process was determined.

An indirect immunofluorescence technique was performed for the odontogenic markers, dentinal matrix protein-1 (DMP-1), and dentinal sialoprotein (DSP) following the protocol reported by Baldion et al. [13]. Briefly, the cells 
$\left(8 \times 10^{3}\right.$ cells/well $)$ were seeded on poly-L-lysine-treated glass coverslips, which were fixed with $4 \%$ paraformaldehyde (PFA), and permeabilized with Triton X-100, to subsequently block with $10 \%$ goat serum. Cells were incubated at $37^{\circ} \mathrm{C}$ with anti-DMP-1 human polyclonal primary antibody produced in rabbit (Sigma-Aldrich), diluted 1:50 in blocking serum. The samples were then incubated with goat Fluorescein isothiocyanate (FITC) conjugated anti-rabbit IgG secondary antibody (Thermo Fisher Scientific) diluted $1: 200$ in PBS at room temperature. The nuclei were counterstained with Hoechst, and the slides were mounted with VectaShield (Vector Laboratories, Inc. Burlingame, CA, USA) for observation under the Zeiss Axio Imager A2 microscope (Göttingen, Germany) with the AxioVision software. The presence or absence of the protein in cells and its location were evaluated in three independent experiments $(n=3)$. In the same way, the procedure for the DSP marker was carried out using the primary polyclonal human antidentin sialophosphoprotein (DSPP) antibody produced in rabbit (Abcam, Cambridge, MA, USA), which is specific for the $\mathrm{N}$-terminal portion that corresponds to natural cleavage by DSP [13].

\subsection{Detection of the TRPV1 Receptor in hOLCs}

2.3.1. TRPV1 Gene Expression. The polymerase chain reaction technique with real-time reverse transcriptase (RT-qPCR) using SYBR Green with the Luna ${ }^{\circledR}$ Universal One RT-qPCR Kit (New England BioLabs; USA) and the CFX96 Real-Time Thermal Cycler detection system (BioRad; Hercules, CA, USA) was used to determine TRPV1 gene expression. Amplification conditions were as follows: retrotranscription for $10 \mathrm{~min}$ at $55^{\circ} \mathrm{C}$, initial denaturation for $1 \mathrm{~min}$ at $95^{\circ} \mathrm{C}, 40$ cycles of amplification with an alignment temperature of $58^{\circ} \mathrm{C}$ using the following primers (Macrogen ${ }^{\circledR}$ ) TRPV1: Forward $5^{\prime}$-GG CTGTCTTCATCATCCTGCT GCT-3' Reverse $3^{\prime}$ GTTCTT GCTTCTCTGTGCGATCTTGT-5' (NM_080706:118 bp) and $\beta$-actin was used as a housekeeping gene: Forward $5^{\prime}$ CGCCGCCAGCTCACCATG-3' Reverse $3^{\prime}$-CACGATGGAGGGGAAGACGG-5' (NM_000576.3:120 bp). The PCR efficiency was calculated using LinRegPCR (Academic Medical Center, AMC, Amsterdam, Netherlands), and the relative quantification of the amplification was performed with Schefe's method $[13,17]$.

For the TRPV1 identification and localization, immunocytochemical and immunohistochemical assays were performed. For this, $8 \times 10^{3}$ cells/well were seeded on poly-Llysine-treated coverslips in a 24 -well plate. After reaching $30 \%$ confluence, they were fixed with $4 \%$ PFA, permeabilized, and incubated with a rabbit primary polyclonal antibody, specific for human TRPV1 (Thermo Fisher Scientific) in blocking serum. Alexa Fluor 594 coupled to streptavidin (Thermo Fisher Scientific) was used for detection. The nuclei were counterstained with Hoechst and were observed in the A2Axio Imager A2 microscope (Zeiss, Göttingen Germany) and analyzed with the AxioVision software. The presence or absence of the protein in cells and its localization were evaluated in three independent experiments $(n=3)$ [13].

\subsection{TRPV1 Functional Evaluation}

2.4.1. TRPV1 Receptor Agonists. Both EUG and CAP (Sigma-Aldrich) were dissolved in dimethylsulfoxide (DMSO) to obtain a stock solution and kept refrigerated at $-20^{\circ} \mathrm{C}$. The final concentration of DMSO was less than $0.1 \%$ $(\mathrm{v} / \mathrm{v})$ in order not to affect the membrane currents action potential and the intracellular $\mathrm{Ca}^{2+}\left(\left[\mathrm{Ca}^{2+}\right] \mathrm{i}\right)$ concentration [8]. The cell viability was evaluated using the resazurin technique to establish the half-maximal effective concentration (EC50) of both substances. $25 \times 10^{3}$ cells/well were cultured in 96-well plates for $20 \mathrm{~h}$. Cells were treated for $1 \mathrm{~h}$ with $0.1 ; 0.5 ; 1 ; 5$ and $10 \mathrm{mM}$ EUG; after the time had elapsed, it was removed, and $4.4 \mu \mathrm{M}$ resazurin (SigmaAldrich) at $10 \% \mathrm{v} / \mathrm{v}$ was added to each well, starting from an initial solution of $44 \mu \mathrm{M}$, and incubated for $1 \mathrm{~h}$ in the incubator at $37^{\circ} \mathrm{C}$ in a humidified atmosphere containing 5\% $\mathrm{CO}_{2}$. Once the incubation time had elapsed, the plates were read in the Infinite M200 spectrofluorometer (Tecan; Männedorf, Switzerland) at a wavelength of $494 / 520 \mathrm{~nm}$ (excitation/emission). With the fluorescence intensity measurement, the reduction percentage of resazurin to resorufin of the treated groups concerning the control of untreated cells was calculated, taken as $100 \%$. Three independent experiments were analyzed, with six replicates each one $(n=18)$. In the same way, cells were exposed to $0.5 ; 1 ; 5$; 10 and $50 \mu \mathrm{M}$ CAP for $1 \mathrm{~h}$ following the same protocol. With the data obtained, the EC50 was calculated by performing the concentration-response curves for each compound using the GraphPad Prism 7.0 software (GraphPad Software, San Diego, CA, USA).

2.4.2. Polymodal Stimuli Assays. Polymodal stimulation assays were performed measuring the $\left[\mathrm{Ca}^{2+}\right] \mathrm{i}$ change using the Fluo4-AM Kit (F14201 Invitrogen, Thermo Fischer Scientific) as criteria to determine the activation of TRPV1 in hOLCs. For this, $25 \times 10^{3}$ cells/well were seeded in 96-well plates in DMEM medium supplemented with $10 \%$ FBS, 100 $\mathrm{IU} / \mathrm{ml}$ penicillin, $100 \mu \mathrm{g} / \mathrm{ml}$ streptomycin, and $10 \mathrm{ng} / \mathrm{ml}$ TGF- $\beta 1$. Cells were loaded with $4 \mu \mathrm{M}$ Fluo4-AM at $37^{\circ} \mathrm{C}$ for $60 \mathrm{~min}$ in the dark. After time elapsed, the Fluo4-AM was removed, and 1x PBS was added for $30 \mathrm{~min}$. Subsequently, the PBS was removed, and each test substance was added. The reading was done in the spectrofluorometer (TECAN, Infinite M200) after $1 \mathrm{~min}$ and $20 \mathrm{~min}$ of exposure at 494/ $520 \mathrm{~nm}$ (excitation/emission). The difference between the fluorescence obtained and the baseline of unstimulated cells was used as an indirect measure of the changes in $\left[\mathrm{Ca}^{2+}\right]$ i. Each experiment was carried out in triplicate with 3 replicates each one $(n=9)$.

For the chemical stimulation test with EUG and CAP, the calculated EC50 was used. For the thermal stimulation assay, cells were subjected to DMEM medium without phenol red in a range of 37 to $49^{\circ} \mathrm{C}$. For the stimulation with different $\mathrm{pHs}$ assay, the basal DMEM medium ( $\mathrm{pH}$ 7.4) was progressively added $1 \mathrm{~N}$ hydrochloric acid $(\mathrm{HCl})$ to acidify it and obtain the $\mathrm{pH}$ of 4,5 , and $6.5 \mathrm{~N}$ sodium hydroxide $(\mathrm{NaOH})$ was added to obtain $\mathrm{pH}$ of $8,9,10,11$, and 12 . The 
$\mathrm{pH}$ was measured using a potentiometer (Hanna Instruments HI 2210, Rhode Island, USA).

2.5. Data Analysis. A spreadsheet of the Excel program (Microsoft Office 2010) was constructed, and the statistical package SPSS Version 23 was used. For the variables with normal distribution, the mean and standard deviation (SD) were used. Qualitative variables were described in terms of frequencies and proportions. A one-way ANOVA analysis of variance with a Tukey post hoc test was used using an alpha value $<0.05$.

\section{Results}

3.1. Obtaining hDPSCs and the Differentiation Process of hOLCs. hDPSCs showed an adequate monolayer adherence to the plastic, with a spindle-like shape and a fibroblast-like morphology, having a good cell proliferation rate with a PDT of $37 \mathrm{~h}$ (Figure 1(a)). They were characterized using flow cytometry to evaluate the expression of specific markers of undifferentiated stem cells. Its mesenchymal phenotype was demonstrated by the positivity for CD90, CD105, and CD73 in more than $95 \%$ of the cells and negativity for the early hematopoietic markers CD14, CD20, CD34, and CD45 (Figure $1(\mathrm{~b})$ ) in less than $1 \%$ of cells and an in vitro differentiation capacity toward several lineages, such as osteoblasts, chondrocytes, and adipocytes (Figure 1(c)).

Subsequently, hDPSCs were differentiated for 7, 14, and 21 days in an odontogenic induction medium to obtain hOLCs. There were no apparent morphological changes during the differentiation process, and an optimal proliferation was maintained (Figure $1(\mathrm{~d})$ ).

Additionally, using immunofluorescence, the odontoblast phenotype of hOLCs was verified at 21 days of differentiation, and the odontogenic markers DMP-1 and DSP were identified. Dental tissue and mammary gland or placenta were used as controls, respectively (Figure 2).

\subsection{Detection of the TRPV1 Receptor in hOLCs}

3.2.1. Evaluation of TRPV1 Receptor $m R N A$ and Determination of Its Presence in hOLCs. RT-qPCR revealed a differential pattern of spatiotemporal expression of the TRPV1 transcripts at 7,14 , and 21 days of differentiation $(p<0.05)$ (Figure 3(a)) regarding $\beta$-actin $(\beta$-ACT). Additionally, agarose gel electrophoresis of the products was performed, and a higher expression of TRPV1 mRNA was observed in differentiated hOLCs at 7, 14, and 21 days, compared to hDPSCs (Figure 3(b)).

The presence and location of the TRPV1 receptor were determined using immunofluorescence (Figure 4).

3.3. TRPV1 Receptor Functional Evaluation. Cell viability was determined using the resazurin technique, and the EC50 was found for 603.5 $\mu \mathrm{M}$ EUG (Figure 5(a)) and 10.1 $\mu \mathrm{M}$ CAP (Figure 5(b)).
3.4. Polymodal Stimuli Assays. The cells were stimulated for 1 min (simulation of immediate exposure) and for $20 \mathrm{~min}$ (simulation of chronic exposure). After stimulation, the measurement of relative fluorescence units (RFU) was performed using spectrofluorimetry (TECAN, Infinite M200). Means \pm SD of three independent experiments with three replicates each $(n=9)$ are shown. Analysis of variance one-way ANOVA and Tukey's post hoc analysis established a statistically significant difference with a $p<0.05$.

3.4.1. Chemical Stimulation. The hOLCs were stimulated with CAP $(10 \mu \mathrm{M})$ and EUG $(603.5$ and $1000 \mu \mathrm{M})$, and unstimulated cells were used as a control. Additionally, vehicle dimethyl sulfoxide (DMSO) $<1 \%$ was evaluated. The results showed that the cells exposed to CAP and EUG had a significant RFU increase, indicating a TRPV1 receptor activation, compared to the control and vehicle (DMSO) for the two evaluated times ( 1 and $20 \mathrm{~min}$ ). Assuming that the stimulation for $20 \mathrm{~min}$ is equivalent to chronic exposure to the compound, it was evident that there was a marked difference between these measurements compared to the immediate exposure (1 min), which demonstrated a marked decrease in receptor activation (Figure 6(a)), related to receptor desensitization.

3.4.2. Thermal Stimulation. In hOLCs stimulated with temperatures $\geq 43^{\circ} \mathrm{C}$, an increase in $\left[\mathrm{Ca}^{2+}\right] \mathrm{i}$ and, consequently, in TRPV1 receptor activation, was observed compared to $37^{\circ} \mathrm{C}$ and $40^{\circ} \mathrm{C}$. There was no difference between the measurements at 1 and 20 min (Figure 6(b)).

3.4.3. Stimulation with Different $p H s$. For the physiological $\mathrm{pH}$ of 7 , used as a reference point, a consistent increase in RFU was observed, which is related to the TRPV1 receptor activation from a $\mathrm{pH}$ of 5 onwards. This activation was more noticeable, specifically at $\mathrm{pH} 5$ and 6 , both in immediate exposure $(1 \mathrm{~min})$ and chronic exposure $(20 \mathrm{~min})$. Additionally, the only group in which a difference was observed between the exposure times ( 1 and $20 \mathrm{~min}$ ) was the one stimulated with a $\mathrm{pH}$ of 4 (Figure 6(c)).

\section{Discussion}

This study demonstrated the presence, localization, and polymodal activation of the TRPV1 receptor in hOLCs. First, the phenotypic characterization of both hDPSCs and hOLCs obtained after odontogenic differentiation could be performed, which is a useful tool for the study of dental sensitivity. Second, using RT-qPCR, it was possible to demonstrate not only the expression of the TRPV1 receptor in these hOLCs, but also an increase in the expression of TRPV 1 transcripts at 7, 14, and 21 days of differentiation in hOLCs, compared to hDPSCs cells $(p<0.05)$. The highest expression at 14 days of differentiation could be related to the fact that, at this stage, cells are characterized as mature secretory odontoblasts. Therefore, it becomes a more specialized sensitive cell that requires a more developed sensory 


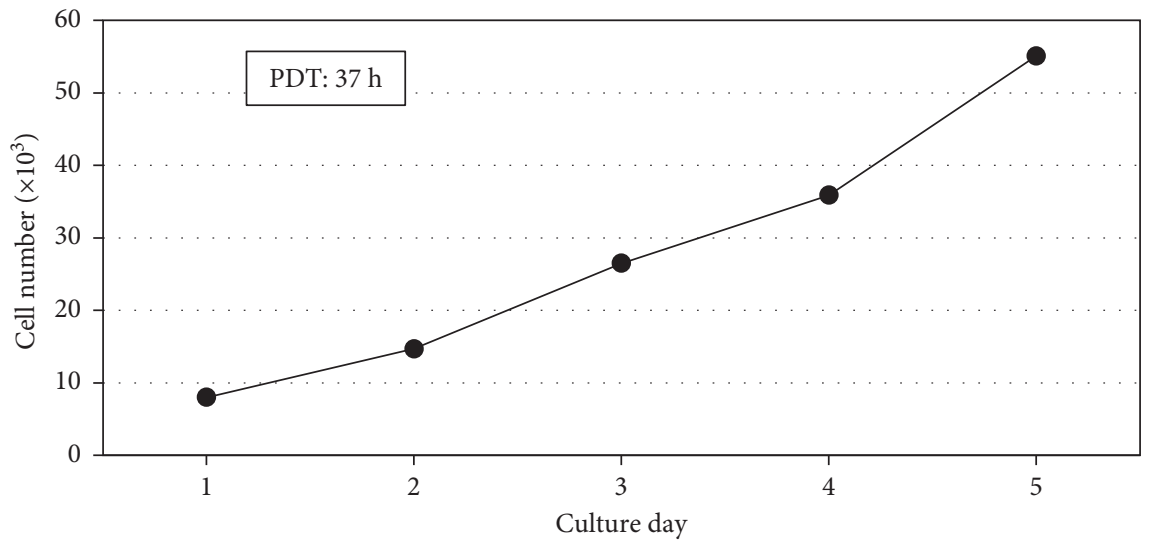

(a)
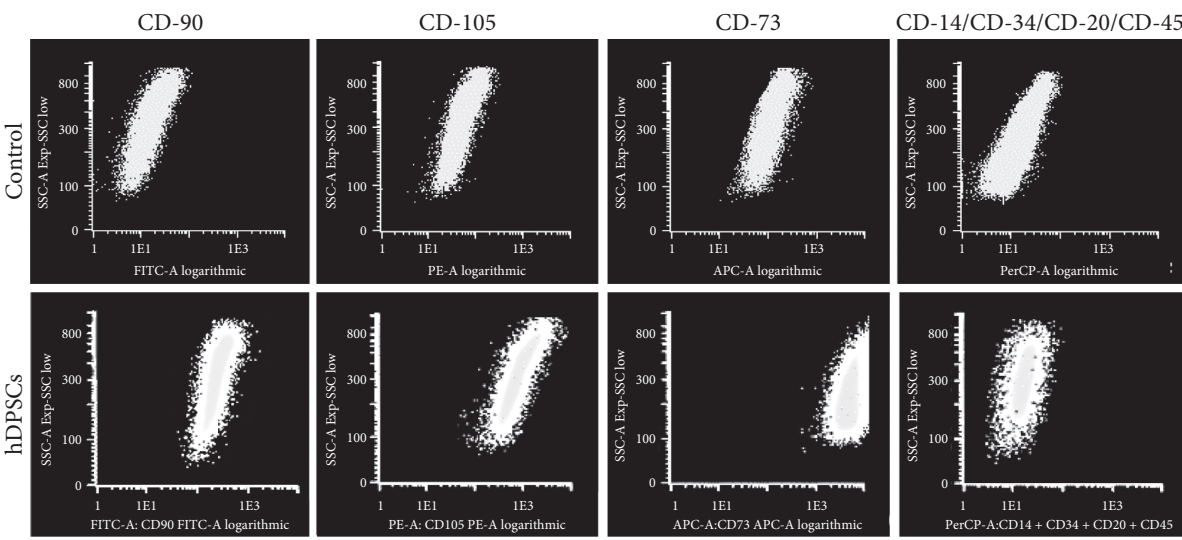

(b)

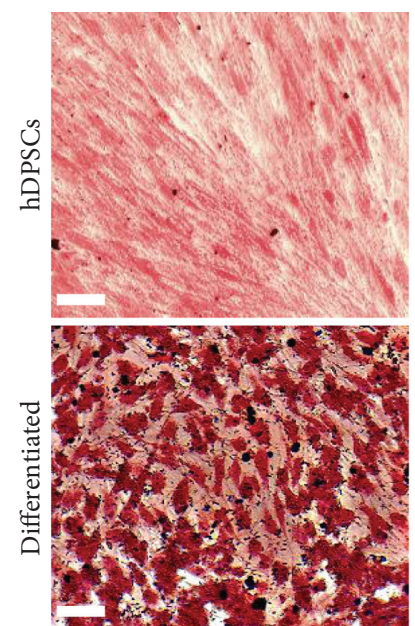

Osteoblasts

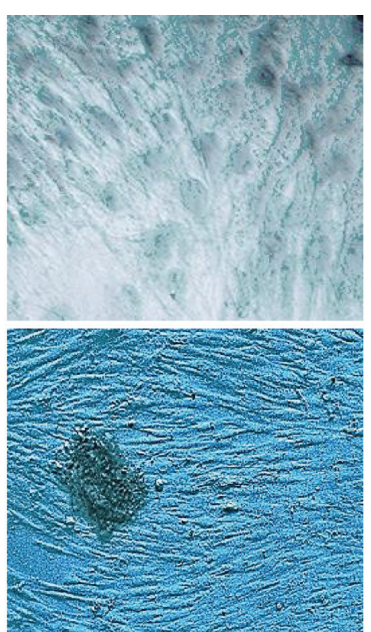

Chondrocytes

(c)

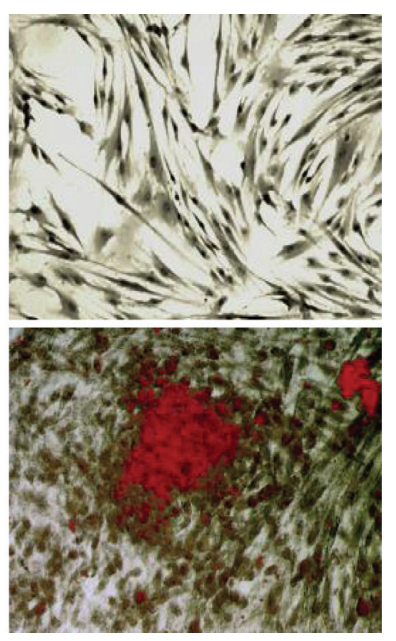

Adipocytes

Figure 1: Continued. 


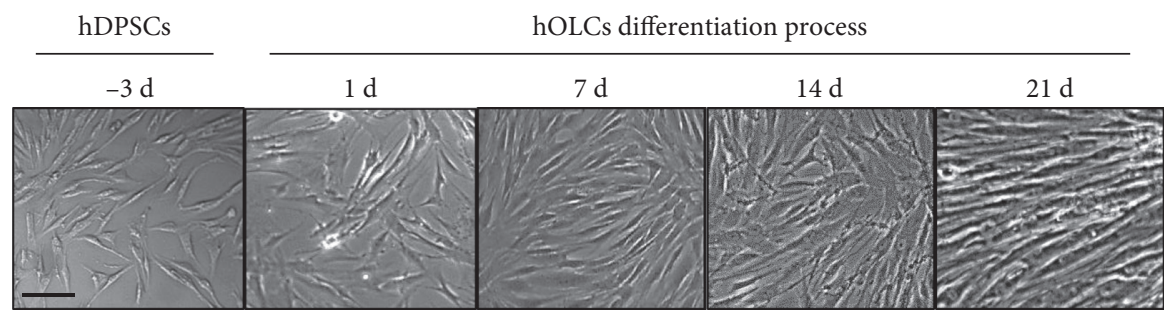

(d)

FIgURE 1: Phenotypic characterization of hDPSCs and morphological cell appearance during the cell differentiation process. (a) The PDT was calculated considering the cell count performed in the first 96 hours (4 days) of cell culture, using a hemocytometer. Results are shown as the average of three independent experiments in triplicate $(n=9)$. (b) The undifferentiated mesenchymal phenotype was verified using flow cytometry by using the cocktail for phenotyping of Miltenyi, which demonstrated positivity for mesenchymal markers CD90, CD105, and CD73 and negativity for the early hematopoietic markers CD14, CD20, CD34, and CD45. A total of 100,000 events were acquired with the use of the FACSCalibur cytometer, and the data were analyzed using FCS Express software. (c) To evaluate the differentiation potential of hDPSCs, they were exposed to differentiation media for the three lineages for 21 days and the respective stains were performed in order to corroborate the acquired phenotype. The osteoblasts were stained with alizarin red, and the formation of mineralization nodules is evidenced. The chondrocytes were stained with Alcian blue, positive labeling of proteoglycans is evidenced, and adipocytes were stained with OilO red; a positive staining of fatty acids is shown. Scale bar: $100 \mu \mathrm{m}$. (d) Phase contrast microscopy images showing hDPSCs with tapered, fibroblastic morphology, as well as hOLCs cells during the differentiation process at 7, 14, and 21 days. A trend toward organized training in parallel lines is shown. Leica DM2500 Microscope (Leica Microsystems; Wetzlar, Germany) was used. Scale bar: $100 \mu \mathrm{m}$.
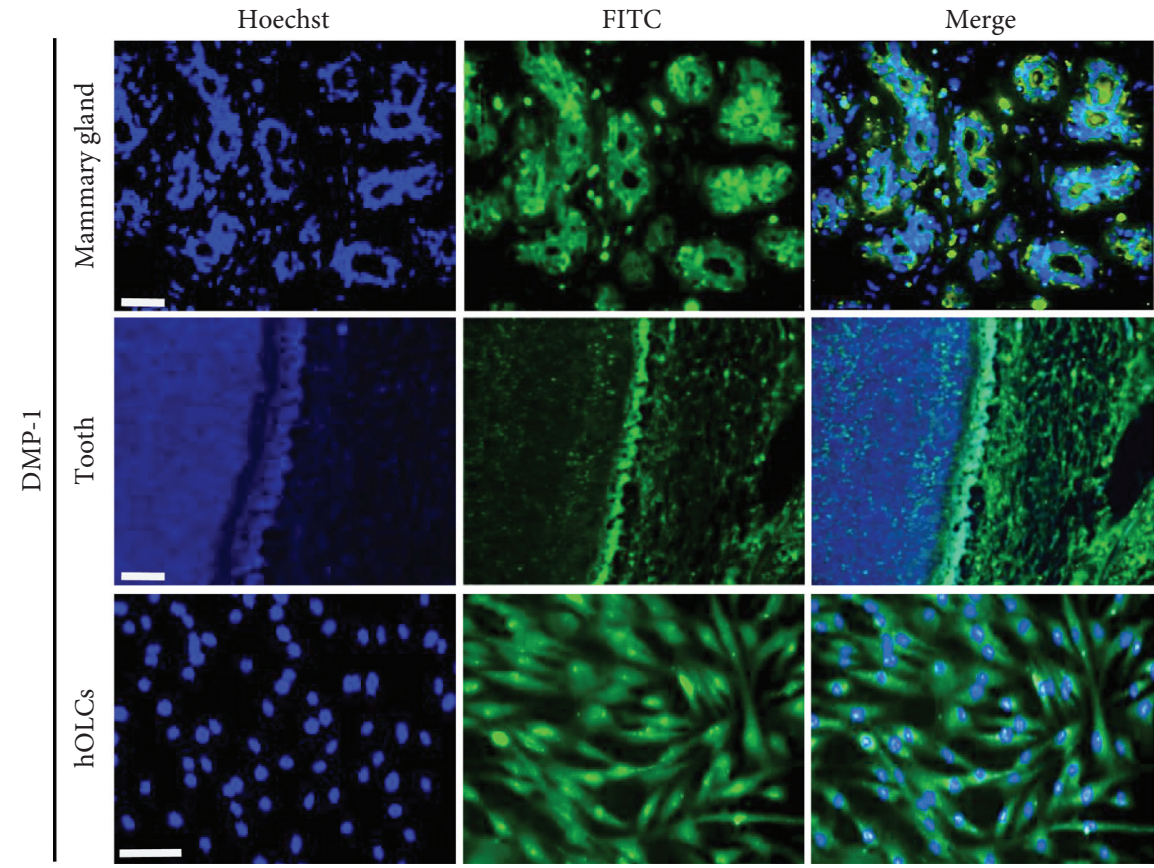

(a)

Figure 2: Continued. 

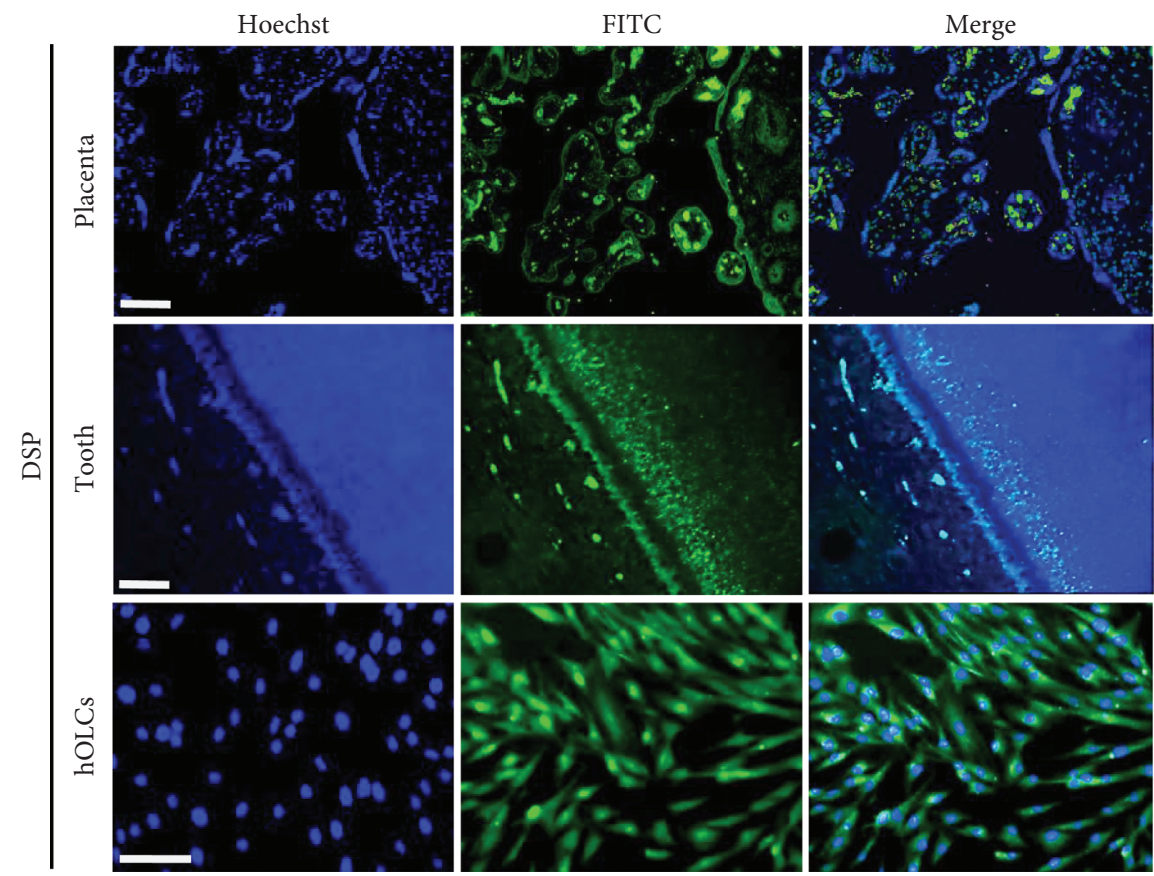

(b)

FIGURE 2: Immunocytochemical detection of odontogenic markers DMP-1 and DSP in hOLCs. Positive immunostaining (green) of tissue control (a) mammary gland for DMP-1 and (b) placenta for DSP. Positive staining of dental tissue in the odontoblast layer and mineralization in front of the dentin. To determine the presence and location of the odontogenic markers in the differentiated cells, an antiDMP-1 (a) or anti-DSP (b) antibody conjugated with FITC (green) was used, and the nuclei were counterstained with Hoechst stain (blue). Note the positivity of these markers in hOLCs, with both a nuclear and cytoplasmic distribution. A Zeiss Axio Imager A2 microscope was used to obtain the images. Scale bar: $50 \mu \mathrm{m}$.

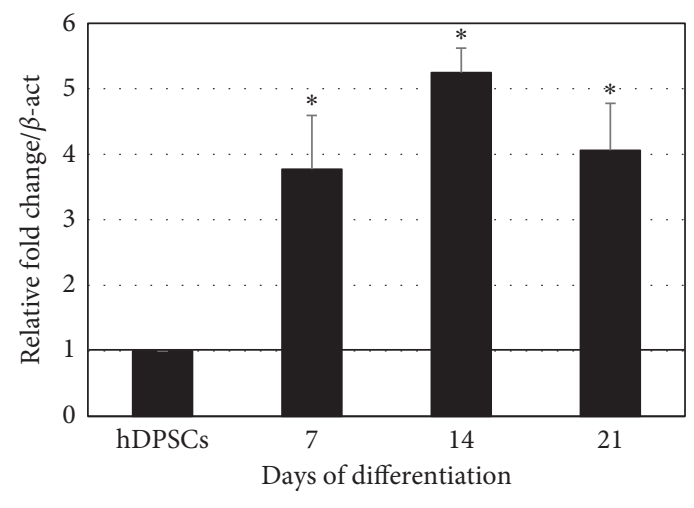

(a)

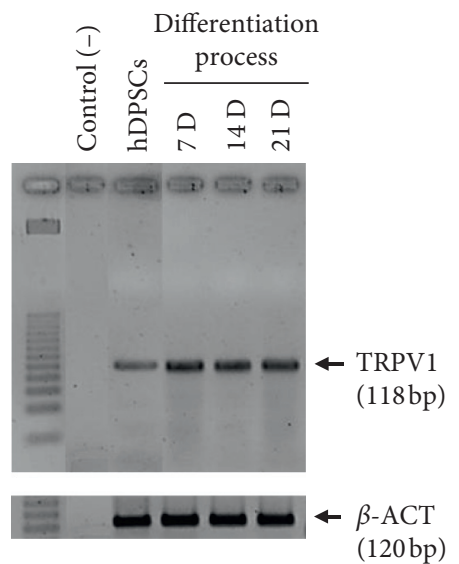

(b)

FIgURE 3: Relative quantification of TRPV1 at different differentiation times using RT-qPCR. (a) Relative quantification of TRPV1 transcripts using RT-qPCR in hOLCs cells at 7, 14, and 21 days of differentiation, compared to hDPSCs, which were used as baseline, and considered as 1 . An overexpression of transcripts was observed for all the differentiation times. Results are presented as mean \pm standard deviation (SD) of three independent experiments in triplicate $(n=9)$. The asterisks show statistically significant differences between hDPSCs cells and the control $(p<0.05)$. (b) Agarose gel electrophoresis $(2 \%)$ of the TRPV1 products of RT-qPCR. An increase in the expression of the transcripts is observed at 7,14, and 21 days of differentiation, compared to hDPSCs. $\beta$-actin $(\beta$-ACT) was used as a housekeeping gene. GelDoc Go System reader was used (BioRad, Hercules, CA, USA). 


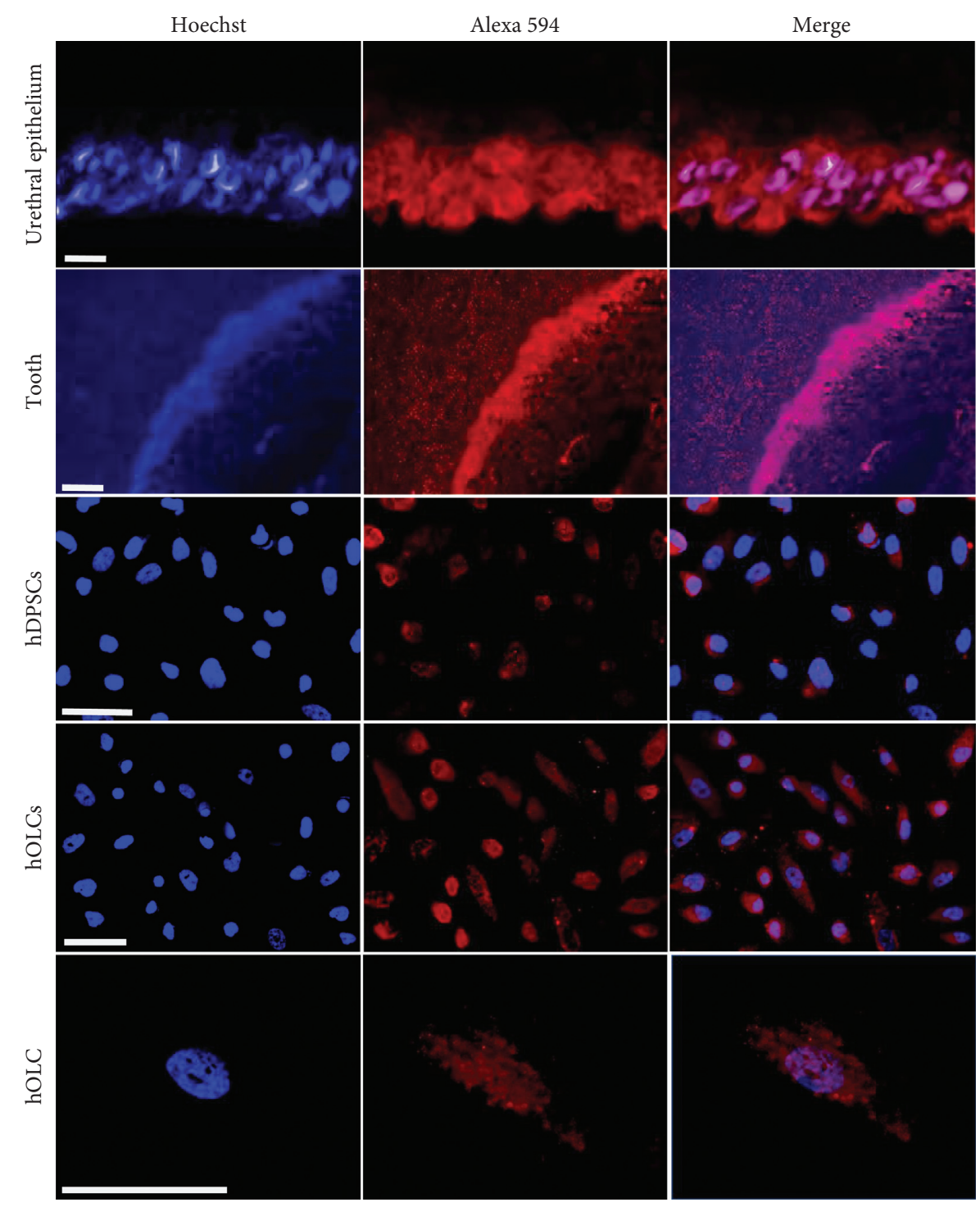

FIGURE 4: Immunocytochemical detection of TRPV1 receptor in hOLCs. Immunocytochemical identification of TRPV1 in the control of urethral epithelial tissue, in dental tissue, in hDPSCs cells, and in hOLCs. Anti-TRPV1 antibody conjugated with Alexa fluor 594 (red) was used to obtain the protein labeling and the nuclei were counterstained with Hoechst stain (blue). Note the positive staining in the dental tissue located in the area of the odontoblast palisade. Additionally, in hOLCs cells, an increase in this immunostaining localized in the membrane is evident, compared to hDPSCs. Zeiss Axio Imager A2 microscope was used. Scale bar: $50 \mu \mathrm{m}$.

function. This suggests that hOLCs could be considered sensitive cells and that such a condition could be associated with the expression of the TRPV1 receptor membrane. Similar results were found using immunocytochemistry. First, in dental tissue, TRPV1 is specifically located in the area of the odontoblast palisade. Secondly, TRPV1 presented a membrane distribution with higher immunostaining in hOLCs than in hDPSCs. Together, these two findings confirm the relationship between the presence of the TRPV1 receptor and the obtention of the odontoblast phenotype $[8,18]$.

TRPV1 receptor activation was carried out under three conditions: chemical stimulation, thermal stimulation, and exposure to different pHs. Regarding chemical stimulation, it was possible to observe a difference in the concentration necessary to activate the TRPV1 receptor. According to the cell type, it was found that the EC50 calculated for EUG was $603.5 \mu \mathrm{M}$ in hOLCs, while the EC50 reported in HEK-293 cells and trigeminal neurons was $1 \mathrm{mM}$ [12]. This evidence allows us to appreciate a difference in the sensitivity to chemical stimulation performed with EUG as an agonist in OD and in other cell models.

In addition, it was possible to observe the TRPV1 receptor activation with CAP at $10 \mu \mathrm{M}$, and with EUG at 1000 and $603.5 \mu \mathrm{M}$, with very similar behaviors. The activation of TRPV1 with CAP in different cell types, which has been previously reported [3-8], is based on the attribution of such activation to the specific binding of CAP with Glu-571 and Thr-551 residues of the receptor, which causes a conformational change that, in turn, induces the opening of the 


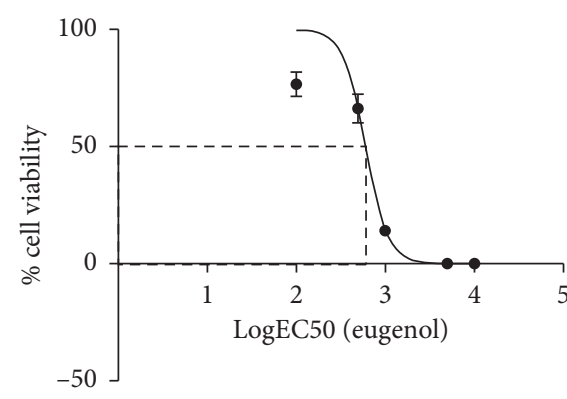

(a)

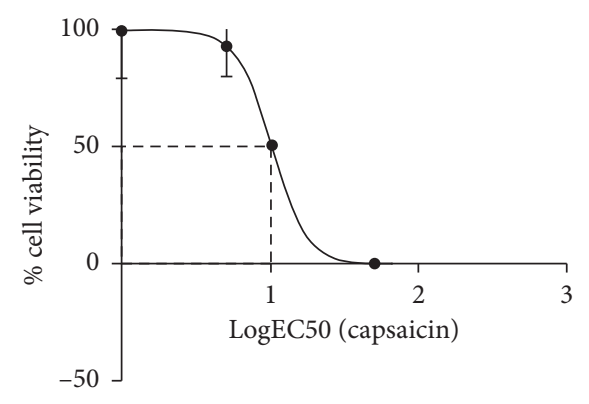

(b)

FIgURE 5: Calculation of EUG and CAP EC50 in hOLCs using resazurin technique. The EC50 was calculated from the resazurin assay in hOLCs exposed to different concentrations of the two compounds. (a) EUG EC50. Concentration range: 10, 5, 1, 0.5, and 0.1 mM. LogEC50: 2.781, equivalent to $603.5 \mu \mathrm{M}$. (b) CAP EC50. Concentration range: 50,10, 5, 1, and $0.5 \mathrm{mM}$. $\operatorname{LogEC} 50: 1.004$, equivalent to $10.1 \mu \mathrm{M}$. GraphPad Prism 7.00 software was used. The curves represent the results of 3 independent experiments with six replicates each $(n=18)$.

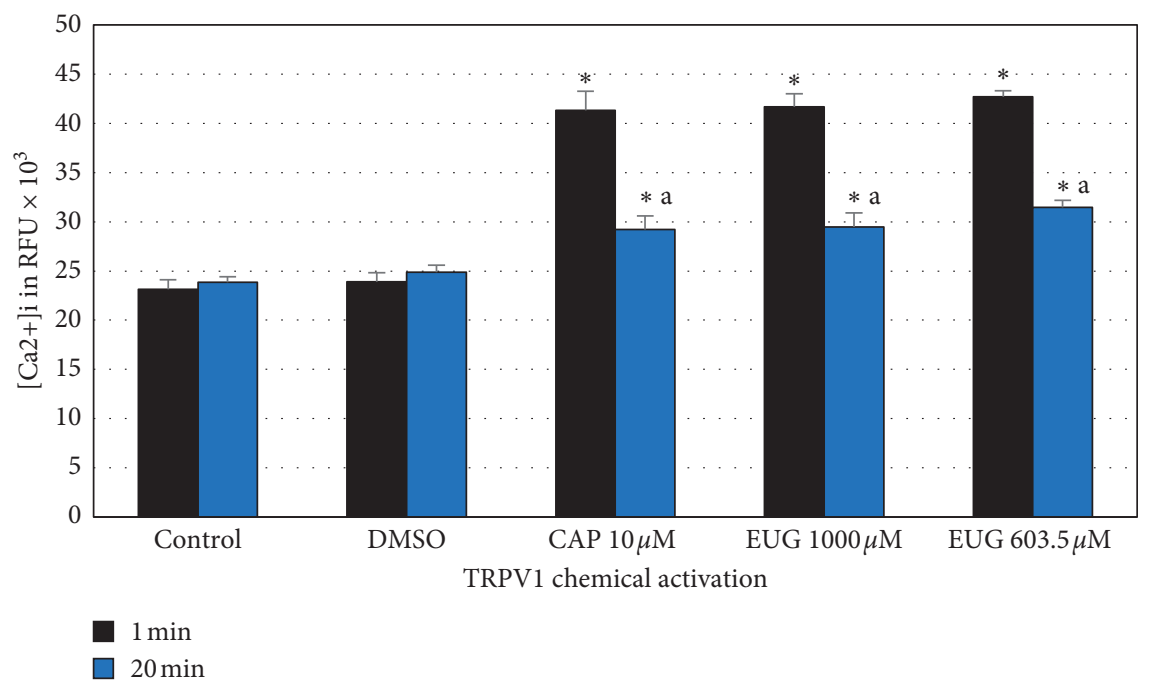

(a)

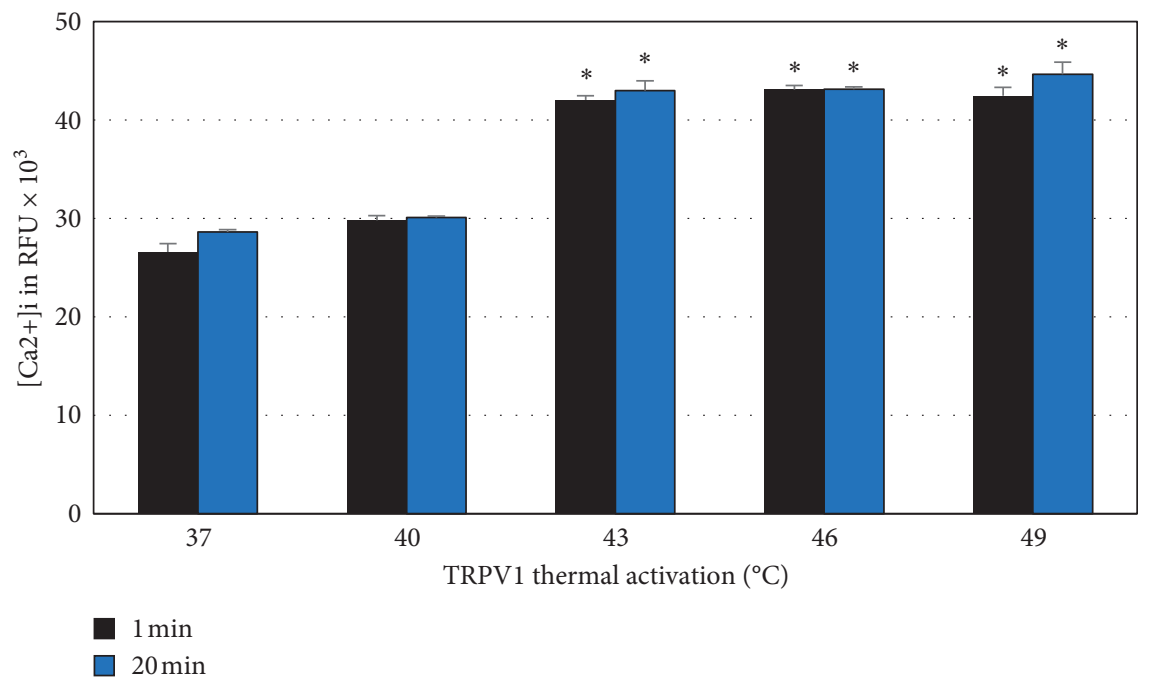

(b)

FIgURE 6: Continued. 


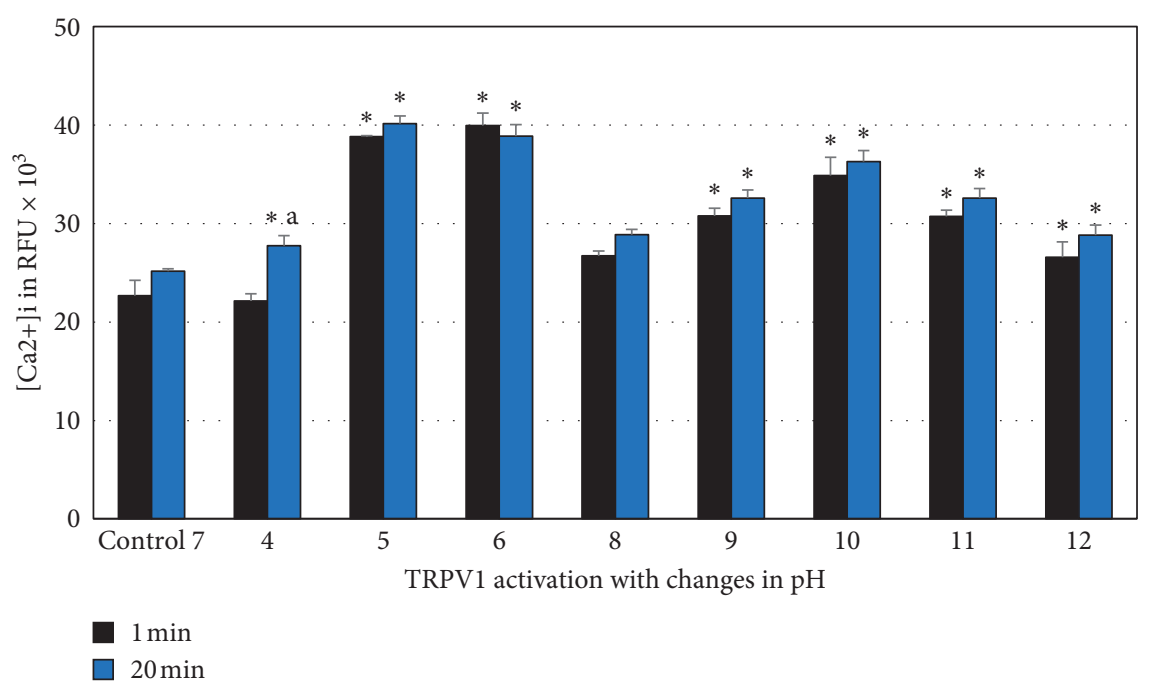

(c)

FIGURE 6: Chemical, thermal, and pH stimuli of TRPV1 receptor in hOLCs. In the polymodal stimulation assays, 1 and 20 min of exposure to the stimulus were evaluated using the Fluo 4 AM probe. (a) Chemical stimulation of the TRPV1 receptor. Statistically significant differences were found between the test groups at the different exposure times evaluated (1 and $20 \mathrm{~min}$ ) with both CAP and EUG. TRPV1 receptor desensitization was confirmed at 20 min with both vanilloid substances, and no differences from the control were identified. (b) Thermal stimulation activation at $43^{\circ} \mathrm{C}$. No statistically significant differences were found between the test groups at the different exposure times evaluated (1 and $20 \mathrm{~min}$ ). (c) Stimulation with changes in $\mathrm{pH}$. Activation was marked at pH 5 and 6 . Relative fluorescence units (RFU) were detected at a wavelength of $494 / 520 \mathrm{~nm}$ (excitation/emission) using a TECAN microplate reader. Results are shown as the mean \pm SD of three independent experiments in triplicate $(n=9)$. Each group was compared to its respective control, and the asterisks show statistically significant differences between them $(p<0.05)$. The lowercase letter (a) shows statistically significant differences between the test groups at the different times evaluated ( 1 and $20 \mathrm{~min})(p<0.05)$.

channel. Some authors hypothesize that this mechanism of chemical receptor activation could be applicable to the entire group of capsaicinoids, including EUG [19].

Second, regarding thermal stimulation, TRPV1 activation was observed in hOLCs at temperatures $\geq 43^{\circ} \mathrm{C}$, a result consistent with that reported in previous studies carried out in human OD [8], mouse OD [4], and rat primary afferent neurons [5]. Previous studies have attributed this thermal activation to two potential complementary mechanisms. On the one hand, it is proposed that the protein kinase A/Akinase anchoring proteins (PKA/AKAP) signaling pathway is involved in the thermal hyperalgesia mechanism through the phosphorylation of a Ser-502 residue located between the TRPV1 S2-S3 linker, which would promote an ionic pore opening [20]; on the other hand, it is suggested that this ionic pore could act as a thermal sensor [21]. However, the lack of clarity regarding the molecular details of TRPV1 activation by increasing the temperature has led to the suggestion of a third mechanism, according to which the ankyrin repeat domain (ARD) could undergo structural changes in response to heat, which could determine the TRPV1 activation [22].

Instead, in terms of exposure to different $\mathrm{pH}$ values, a significant activation of the TRPV1 receptor in hOLCs subjected to acidic $\mathrm{pH}$ (5 and 6), both in the immediate (1 min) and chronic (20 min) exposure, was identified. This is in agreement with the findings of a previous report, which registered a TRPV1 receptor activation at a pH lower than 6 [6]. The results demonstrated a discrepancy between the two exposure times ( 1 and $20 \mathrm{~min}$ ) at $\mathrm{pH} 4$, with a significant activation with a sustained exposure for $20 \mathrm{~min}$. These findings are consistent with the functional study by Tsumura et al. on rat OD, in which receptor activation was demonstrated after 2 min of exposure using an acidic solution at the same $\mathrm{pH}$, an activation that was conserved in subsequent measurements [6].

Additionally, receptor activation was observed at basic pHs-between 9 and 12-an unprecedented report on previous studies in OD. Within this range, the most significant activation occurred at $\mathrm{pH} 10$, although it was not as remarkable as in the case of acidic pHs [6]. Previous investigations carried out in mouse GT neurons and in transfected HEK-293 cells demonstrated the activation of TRPV1 by exposure to ammonium $\left(\mathrm{NH}_{4}{ }^{+}\right)$and by intracellular alkalinization, which causes the deprotonation of the Hys-378 residue in the cytoplasmic domain of the receptor. This, in turn, would cause new intra- and intermolecular interactions, leading to a conformational change that would translate into receptor activation. Such activation occurred at a $\mathrm{pH}>8$ and at a $\mathrm{pH}$ of 7.8-9.5 in the first and second systems, respectively, which is consistent with the findings of our study [23].

At this point, the activation of the TRPV1 receptor in hOLCs is taken for granted at the three conditions described, namely chemical stimulation, thermal stimulation, and exposure to different $\mathrm{pH}$ values. Next, it is important to raise the hypotheses that have tried to establish the possible mechanism by which such activation translates into pain and its role in dental nociception. 
First, it has been proposed a possible "neuro-odontoblast" interaction due to TRPV1 receptor activation, caused by thermal or mechanical stimulation, due to the entry of $\left[\mathrm{Ca}^{2+}\right] \mathrm{i}$ into the $\mathrm{OD}$, which can cause the depolarization of its membranes. In turn, the entry of $\mathrm{Ca}^{2+}$ and membrane depolarization would release stimulant "transmitters" that could activate the nearby nerve endings $[3,24]$.

Subsequently, it was possible to establish an association between the influx of $\mathrm{Ca}^{2+}$ involved in TRPV1 receptor activation and the stimulation of adenosine triphosphate (ATP) production in OD. This finding contributes to the elucidation of the communication mechanism between OD and nerve fibers thanks to the presence of purinergic-type receptors $\mathrm{P} 2 \mathrm{X}$ (ionotropic) and $\mathrm{P} 2 \mathrm{Y}$ (G protein-coupled), both in OD and nerve endings. ATP release mechanisms, namely $\mathrm{Ca}^{2+-}$ dependent mobilization of vesicles, and transportation of ATP via connexin 43 or pannexin 1 (PANX-1) as a membrane or hemichannel transporters, have been recorded [2, 25-27]. These findings offer strong support for the hypothesis of the neuro-odontoblast interaction and for the postulate of the sensory implications of ATP release.

Thus, the findings of the relationship between the TRPV1 receptor and nociceptive transmission suggest that research aimed at achieving analgesia could be devoted to the study of the desensitization of this receptor. Regarding receptor desensitization via chemical stimulation, such as that found using EUG in our study, several studies clarify and support the achievement of analgesia with the use of vanilloids [11].

It is possible to characterize desensitization caused by the chronic exposure to agonists $(20 \mathrm{~min})$, as a process remarkably dependent on the entry of $\mathrm{Ca}^{2+}$ and the activation of several intracellular signaling pathways due to the importance of $\mathrm{Ca}^{2+}$ as a second messenger. Previous evidence showed that in Chinese hamster ovary derived cells (CHO) transfected and stimulated with CAP, the increase in $\left[\mathrm{Ca}^{2+}\right] \mathrm{i}$ caused marked TRPV1 receptor desensitization, induced by the intracellular dephosphorylation of Ser-116 residue. It has been proposed that the vanilloid substance would be responsible for inactivating PKA, thus leading to a TRPV1 receptor desensitized state [28], similar to that obtained by the action of calcineurin $[29,30]$.

A desensitization mechanism in rat dorsal root ganglion neurons (DRG) has also been proposed for activating calcineurin, which would lead to the dephosphorylation of residues Ser-502 and Thr-704 and, therefore, to TRPV1 desensitization which would lead to the activation of the enzyme $\mathrm{Ca}^{2+} /$ calmodulin kinase II (CaMKII), which would rephosphorylate the receptor at residues Ser-502 and Thr704. This process of rephosphorylation returns the TRPV1 receptor to its activation capacity, provided that other important residues, such as those mentioned above, are previously phosphorylated by PKA or protein kinase $\mathrm{C}$ (PKC). The authors highlight this balance between phosphorylation and dephosphorylation, which could be more complex and involve more enzymatic signaling pathways [31].

Additionally, it has been demonstrated a desensitization mechanism mediated by calmodulin binding to a 35-amino- acid segment in the C-terminal portion of TRPV1 in HEK293 cells [32]. In addition, a subsequent study reported a calmodulin binding domain located in the N-terminal portion of TRPV1, which was made up of a 33-amino-acid section adjacent to the ARD [33]. Likewise, the importance of this ARD section has been previously mentioned [33], insofar as an ATP is attached to it as a "sensitizer" that, in conjunction with phosphatidylinositol 4,5-bisphosphate (PIP2), is ready to be activated. After the activation of TRPV1, the influx of $\left[\mathrm{Ca}^{2+}\right] \mathrm{i}$ would cause the release of ATP and the degradation of PIP2 via calmodulin, which leads to receptor desensitization $[34,35]$.

Finally, another study carried out in rat DRG neurons and in HEK-293 cells demonstrated that a chronic exposure (20 $\mathrm{min})$ to CAP $(100 \mathrm{~nm}$ and $1 \mu \mathrm{M}$, respectively) promotes the internalization and degradation of the receptor in a manner that depends on dose, time, and $\mathrm{Ca}^{2+}$ concentration. The aforementioned internalization by the endocytic pathway is modulated by PKA [36]. In addition, it has been found that PKA actively participates in the functional insertion of TRPV1 in the plasma membrane; therefore, its inactivation, caused by CAP, would induce a reduction in membranal TRPV1 as an additional mechanism. Thus, the available evidence indicates that chronic exposure to vanilloids could be used to modulate the membrane expression of TRPV1 [36].

In summary, multiple mechanisms of chemical desensitization with vanilloids have been reported, namely, TRPV1 dephosphorylation by calcineurin, calmodulin-dependent kinases, inactivation of PKA [28-30], calmodulin binding [32, 33], ATP release or depletion of PIP2 from the plasma membrane $[34,35]$, and internalization and degradation of the membrane receptor TRPV1 [36]. It should be noted that all the aforementioned mechanisms show significant potential to achieve analgesia. As has been recognized throughout this study, such mechanisms have been studied mainly in neuronal cultures of DRG and GT of rats and mice, in cultures of transfected HEK-293 cells, and in cultures of transfected $\mathrm{CHO}$ cells. However, to date, no study investigating these desensitization mechanisms in OD has been reported.

Consequently, regarding desensitization in OD, our study was able to establish that a higher concentration of EUG was required to achieve the same effect induced by CAP after a 20min exposure $(10.1 \mu \mathrm{M}$ CAP and $603.5 \mu \mathrm{M}$ EUG). Some authors have proposed that the response patterns of EUG are distinct from those of CAP. They suggested that TRPV1independent mechanisms also appear to be involved in the pharmacological effects of EUG [12]. Unlike CAP, EUG has been widely used in dentistry and its efficacy for relieving toothache has been extensively demonstrated due to its antioxidant effect [37], its antinociceptive effect (related to the inhibition of voltage-gated sodium and calcium channel currents) $[38,39]$, its anti-inflammatory effect (related to significant inhibition of PGE2 production and to a suppression of the cyclooxygenase-2 (COX-2) gene expression) [40], and its antimicrobial effect (related to its broad-spectrum action against Gram-positive and Gram-negative bacteria, fungi, and virus) [41]. 
Regarding receptor desensitization by thermal stimulation, in this study, no evidence of desensitization induced by this type of stimulus was found, with no variation between the measurements at $1 \mathrm{~min}$ and after $20 \mathrm{~min}$ of exposure. These results are consistent with the absence of reports of thermal stimulation-induced receptor desensitization in the available literature. Regarding the receptor desensitization by exposure to different $\mathrm{pH}$ levels, no evidence in favor of it was found in the present study. An earlier study obtained TRPV1 receptor desensitization in a single instance through exposure to an acidic solution at $\mathrm{pH}$ 5.5. Furthermore, it was observed that, unlike the stimulation induced by vanilloids, desensitization would occur by a mechanism independent of CaMKII, which suggests that the process involves other factors and signaling pathways [31].

Finally, the clinical importance of the evidence found in the present study lies in that, although EUG has fallen into disuse in dentistry because of its interference with composite resin polymerization, it has potential in the chemical activation and consequent desensitization of TRPV1 receptor. This projects it as a therapeutic alternative for dentinal hypersensitivity. This possibility is, of course, mediated by future research, which may support the clinical use of this vanilloid.

Additionally, to the thermal activation of the TRPV1 receptor, it must be considered that the pulp-dentinal complex is permanently exposed to high temperatures, typical of the consumption of hot foods or drinks. Additionally, in clinical contexts, such thermal activation can be caused by dental protocols or the use of dental materials with exothermic reactions. It should be remembered that all these procedures could activate TRPV1 receptors, which could cause pain or postoperatory sensitivity.

Furthermore, some dental materials used in clinical practice involve the exposure of the pulp-dentinal complex to varied $\mathrm{pHs}$-basic ones, such as calcium hydroxide, or acidic ones, such as orthophosphoric acid, polyacrylic acid, some self-etching adhesives, or zinc phosphate cement, among others. For this reason, the study of the activation mechanisms of TRPV1, or other receptors of this family, associated with the exposure to different $\mathrm{pH}$ values, is necessary to improve clinical practice and to possibly relieve sensitivity after certain dental procedures.

In summary, the present study demonstrated the presence, membrane localization, and the TRPV1 receptor polymodal activation in a hOLC model. These findings are important because they are considered as the initial step for the construction of a study model of pulp pain, which represents a contribution to the development of therapeutic alternatives for dentinal hypersensitivity based on EUG as a desensitizing agent.

\section{Conclusions}

Within the aims proposed in this study, it was possible to demonstrate, based on evidence, the expression and localization of the TRPV1 receptor in a hOLC model, which represents a contribution of singular relevance to understanding the complexity of dentinal sensitivity. First, the present study demonstrated that the TRPV1 receptor is activated in response to a wide spectrum of conditions, namely, chemical stimulation, thermal stimulation, and exposure to different $\mathrm{pH}$ levels. Taken together, these results indicate that TRPV1 functions as an integrator for a variety of sensory inputs. Second, the present study made it possible to establish that the TRPV1 receptor exhibits a desensitization capacity under stimulation with the vanilloid agonist EUG, similar to that reported for the use of CAP. These findings represent a significant contribution to the study of analgesia and the control of dentinal hypersensitivity and are projected as the basis for the development of a therapeutic alternative for this pathology. Finally, it should be remembered that dentinal hypersensitivity is not only a frequent reason for consultation in dental practice but also that, at present, procedures aimed at treating it show a high therapeutic failure rate.

\section{Data Availability}

The data used to support the findings of this study are available from the corresponding author upon request.

\section{Ethical Approval}

This work was approved by the Ethics Committee of Universidad Nacional de Colombia. Facultad de Odontología. Sede Bogotá (B.CIEFO-122-18).

\section{Conflicts of Interest}

The authors declare that there are no conflicts of interest regarding the publication of this paper.

\section{Acknowledgments}

The authors are especially grateful to Dr. Myriam VelandiaRomero and Dr. Jaime E. Castellanos from virology research group of the Universidad El Bosque and the pathology service of the Fundación Santa Fe. Bogotá, Colombia. This work was supported by grant from Universidad Nacional de Colombia "Convocatoria para el fortalecimiento de alianzas interdisciplinarias y creación artística de la Universidad Nacional de Colombia, Sede Bogotá 2018”. Hermes Code [42183].

\section{References}

[1] J. W. Kim and J.-C. Park, "Dentin hypersensitivity and emerging concepts for treatments," Journal of Oral Biosciences, vol. 59, no. 4, pp. 211-217, 2017.

[2] A. Solé-Magdalena, M. Martínez-Alonso, and C. A. Coronado, "Molecular basis of dental sensitivity: the odontoblasts are multisensory cells and express multifunctional ion channels," Annals of Anatomy, vol. 215, Article ID 28954208, 2018.

[3] R. Okumura, K. Shima, and T. Muramatsu, "The odontoblast as a sensory receptor cell? the expression of TRPV1 (VR-1) channels," Archives of Histology and Cytology, vol. 68, no. 4, Article ID 16477145, 2005. 
[4] R. Son, Y. M. Yang, and J. H. Hong, "Odontoblast TRP channels and thermo/mechanical transmission," Journal of Dental Research, vol. 88, no. 11, Article ID 19828889, 2009.

[5] C. K. Park, S. K. Mi, and Z. Fang, "Functional expression of thermo-transient receptor potential channels in dental primary afferent neurons: implication for tooth pain," Journal of Biological Chemistry, vol. 281, no. 25, Article ID 16595689, 2006.

[6] M. Tsumura, U. Sobhan, and T. Muramatsu, "TRPV1-mediated calcium signal couples with cannabinoid receptors and sodium-calcium exchangers in rat odontoblasts," Cell Calcium, vol. 52, no. 2, Article ID 22656960, 2012.

[7] M. Sato, U. Sobhan, and M. Tsumura, "Hypotonic-induced stretching of plasma membrane activates transient receptor potential vanilloid channels and sodium-calcium exchangers in mouse odontoblasts," Journal of Endodontics, vol. 39, no. 9, Article ID 23683279, 2013.

[8] I. A. El Karim, G. J. Linden, and T. M Curtis, "Human odontoblasts express functional thermo-sensitive TRP channels: implications for dentin sensitivity," Pain, vol. 152, no. 10, Article ID 21168271, 2011.

[9] C. Flegel, N. Schöbel, and J. Altmüller, "RNA-Seq analysis of human trigeminal and dorsal root ganglia with a focus on chemoreceptors," PLoS One, vol. 10, no. 6, Article ID 26070209, 2015.

[10] G. M. Story, A. M. Peier, and A. J. Reeve, "ANKTM1, a TRPlike channel expressed in nociceptive neurons, is activated by cold temperatures," Cell, vol. 112, no. 6, Article ID 12654248, 2003.

[11] V. Fattori, M. S. N. Hohmann, and A. C. Rossaneis, "Capsaicin: current understanding of its mechanisms and therapy of pain and other pre-clinical and clinical uses," Molecules, vol. 21, no. 844, Article ID 27367653, 2016.

[12] B. H. Yang, Z. G. Piao, and Y. B. Kim, "Activation of vanilloid receptor 1 (VR1) by eugenol," Journal of Dental Research, vol. 82, no. 10, Article ID 14514756, 2013.

[13] P. A. Baldion, M. L. Velandia-romero, and J. E. Castellanos, "Odontoblast-like cells differentiated from dental pulp stem cells retain their phenotype after subcultivation," International Journal of Cell Biology, vol. 2018, Article ID 6853189, 2018.

[14] V. Roth, "Doubling time computing," 2006, http://www. doubling-time.com/compute.php.

[15] M. Dominici, K. Le Blanc, and I. Mueller, "Minimal criteria for defining multipotent mesenchymal stromal cells. the international society for cellular therapy position statement," Cytotherapy, vol. 8, no. 4, Article ID 16923606, 2006.

[16] L. A. Mesentier-Louro, C. Zaverucha-Do-Valle, and A. J. Da Silva, "Distribution of mesenchymal stem cells and effects on neuronal survival and axon regeneration after optic nerve crush and cell therapy," PLoS One, vol. 9, no. 10, Article ID 25347773, 2014.

[17] J. H. Schefe, K. E. Lehmann, I. R. Buschmann, T. Unger, and H. Funke-Kaiser, "Quantitative real-time RT-PCR data analysis: current concepts and the novel "gene expression's $\mathrm{C}$ T difference" formula," Journal of Molecular Medicine, vol. 84, no. 11, pp. 901-910, 2006.

[18] W. Wen, K. Que, and C. Zang, "Expression and distribution of three transient receptor potential vanilloid (TRPV) channel proteins in human odontoblast-like cells," Journal of $\mathrm{Mo}$ lecular Histology, vol. 48, no. 5-6, Article ID 28905239, 2017.

[19] F. Yang, X. Xiao, and W. Cheng, "Structural mechanism underlying capsaicin binding and activation of the TRPV1 ion channel," Nature Chemical Biology, vol. 11, no. 7, Article ID 26053297, 2015.

[20] P. K. Rathee, C. Distler, and O. Obreja, "PKA/AKAP/VR-1 module: a common link of gs -mediated signaling to thermal hyperalgesia," Journal of Neurosciences, vol. 22, no. 11, Article ID 12040081, 2002.

[21] F. Zhang, A. Jara-oseguera, and T. Chang, "Heat activation is intrinsic to the pore domain of TRPV1," Proceedings of the National Academy of Sciences, vol. 115, no. 2, Article ID 29279388, 2018.

[22] E. Ladrón-de-Guevara, L. Dominguez, and G. E. RangelYescas, "The contribution of the ankyrin repeat domain of TRPV1 as a thermal module," Biophysical Journal, vol. 118, no. 4, Article ID 31757360, 2020.

[23] A. Dhaka, V. Uzzell, and A. E. Dubin, "TRPV1 is activated by both acidic and basic pH," Journal of Neurosciences, vol. 29, no. 1, Article ID 19129393, 2009.

[24] H. Magloire, M.-L. Couble, B. Thivichon-Prince, J.-C. Maurin, and F. Bleicher, "Odontoblast: a mechano-sensory cell," Journal of Experimental Zoology Part B: Molecular and Developmental Evolution, vol. 312B, no. 5, pp. 416-424, 2009.

[25] F. Bleicher, "Odontoblast physiology," Experimental Cell Research, vol. 325, no. 2, pp. 65-71, 2014.

[26] M. Sato, T. Furuya, and M. Kimura, "Intercellular odontoblast communication via ATP mediated by pannexin-1 channel and phospholipase C-coupled receptor activation," Frontiers in Physiology, vol. 6, no. 326, Article ID 26617529, 2015.

[27] Y. Shibukawa, M. Sato, and M. Kimura, "Odontoblasts as sensory receptors: transient receptor potential channels, pannexin-1, and ionotropic ATP receptors mediate intercellular odontoblast-neuron signal transduction," Pflugers Archiv, vol. 467, no. 4, Article ID 24939701, 2015.

[28] G. Bhave, W. Zhu, and H. Wang, "cAMP-dependent protein kinase regulates desensitization of the capsaicin receptor (VR1) by direct phosphorylation," Neuron, vol. 35, no. 4, Article ID 12194871, 2002.

[29] D. P. Mohapatra and C. Nau, "Desensitization of capsaicinactivated currents in the vanilloid receptor TRPV1 is decreased by the cyclic amp-dependent protein kinase pathway," Journal of Biological Chemistry, vol. 278, no. 50, pp. 5008050090, 2003.

[30] D. P. Mohapatra and C. Nau, "Regulation of $\mathrm{Ca}^{2+-}$ dependent desensitization in the vanilloid receptor TRPV1 by calcineurin and cAMP-dependent protein kinase," Journal of Biological Chemistry, vol. 280, no. 14, pp. 13424-13432, 2005.

[31] J. Jung, J. S. Shin, and S. Lee, "Phosphorylation of vanilloid receptor 1 by $\mathrm{Ca}^{2+} /$ calmodulin- dependent kinase II regulates its vanilloid binding," Journal of Biological Chemistry, vol. 279, no. 8, Article ID 14630912, 2004.

[32] M. Numazaki, T. Tominaga, K. Takeuchi, N. Murayama, H. Toyooka, and M. Tominaga, "Structural determinant of TRPV1 desensitization interacts with calmodulin," Proceedings of the National Academy of Sciences, vol. 100, no. 13, pp. 8002-8006, Article ID 12808128, 2003.

[33] T. Rosenbaum, A. Gordon-shaag, M. Munari, and S. E. Gordon, "Ca2+/calmodulin modulates TRPV1 activation by capsaicin," Journal of General Physiology, vol. 123, no. 1, Article ID 14699077, 2004.

[34] P. V. Lishko, E. Procko, X. Jin, C. B. Phelps, and R. Gaudet, "The ankyrin repeats of TRPV1 bind multiple ligands and modulate channel sensitivity," Neuron, vol. 54, no. 6, pp. 905-918, 2007.

[35] B. Liu, C. Zhang, and F. Qin, "Functional recovery from desensitization of vanilloid receptor TRPV1 requires 
resynthesis of phosphatidylinositol 4,5-bisphosphate," Journal of Neuroscience, vol. 25, no. 19, pp. 4835-4843, 2005.

[36] L. Sanz-Salvador, A. Andrés-Borderia, A. Ferrer Montiel, and R. Planells Cases, "Agonist- and $\mathrm{Ca}^{2+-}$ dependent desensitization of TRPV1 channel targets the receptor to lysosomes for degradation," Journal of Biological Chemistry, vol. 287, no. 23, pp. 19462-19471, 2012.

[37] S. F. Hamed, Z. Sadek, and A. Edris, "Antioxidant and antimicrobial activities of clove bud essential oil and eugenol nanoparticles in alcohol-free microemulsion," Journal of Oleo Science, vol. 61, no. 11, pp. 641-648, 2012.

[38] M. H. Lee, K. Y. Yeon, and C. K. Park, "Eugenol inhibits calcium currents in dental afferent neurons," Journal of Dental Research, vol. 84, no. 9, Article ID 16109996, 2005.

[39] C. K. Park, K. Kim, and S. J. Jung, "Molecular mechanism for local anesthetic action of eugenol in the rat trigeminal system," Pain, vol. 144, no. 1-2, Article ID 19376653, 2009.

[40] S. S. Kim, O. J. Oh, and H. Y. Min, "Eugenol suppresses cyclooxygenase- 2 expression in lipopolysaccharide-stimulated mouse macrophage RAW264.7 cells," Life Sciences, vol. 73, no. 3, Article ID 12757841, 2003.

[41] A. Marchese, R. Barbieri, and E. Coppo, "Antimicrobial activity of eugenol and essential oils containing eugenol: a mechanistic viewpoint," Critical Reviews in Microbiology, vol. 43, no. 6, Article ID 28346030, 2017. 